\title{
VISÃO INTERPRETATIVA DE REFORMA TRIBUTÁRIA PROGRESSIVA CONCILIADA AO DEVER DE PAGAR TRIBUTOS
}

\section{ARTIGO ORIGINAL}

MARTIN, Samuel Antônio ${ }^{1}$

MARTIN, Samuel Antônio. Visão interpretativa de reforma tributária progressiva conciliada ao dever de pagar tributos. Revista Científica Multidisciplinar Núcleo do Conhecimento. Ano 05, Ed. 08, Vol. 14, pp. 49-63. Agosto de 2020. ISSN: 2448-0959, Link de acesso: https://www.nucleodoconhecimento.com.br/lei/visao-interpretativa

\section{RESUMO}

A pesquisa em questão busca tratar sobre uma melhor interpretação a respeito de uma modificação no modo como se executa o dever da tributação, considerando o problema da desigualdade social existente em nosso país e tendo em vista a forma pelas quais a tributação ocorre, levando em consideração parâmetros mais voltados para o consumo do que para a renda. Para demonstrar isso, tornou-se necessária a realização de uma análise metodológica muito criteriosa, consultando a doutrina, bem como a legislação tributária existente e, principalmente, a Constituição Federal de 1988, sobretudo através dos princípios constitucionais tributários. Os principais objetivos desta pesquisa são, sobretudo, apresentar uma melhor forma de estabelecer novas diretrizes a respeito deste tema no Brasil e conscientizar as pessoas a respeito de uma maior visão acerca da tributação. No entanto, há de se concluir que é necessária a atuação do Estado, neste sentido, para reformar de modo igualitário a tributação no Brasil. Além disso, também é necessário que nós, sociedade, lutemos para realizar tais mudanças, nos integrando com o poder público, a fim de ocorrer reformas profundas na tributação brasileira e redução das desigualdades sociais.

\footnotetext{
${ }^{1}$ Estudante de Direito da UFLA.
} 
Palavras-chave: Constituição, progressividade, tributação, conflito.

\section{INTRODUÇÃO}

O atual sistema tributário brasileiro é um mecanismo bastante elaborado que, em tese, possui um comprometimento com a igualdade social e vem, há anos, criando complexos elementos de tributação que garantem uma arrecadação nacional satisfatória. Tutelado primordialmente pela nossa Constituição Federal de 1988, o sistema tributário nacional é um efetivo viés de garantia do aumento de renda da população, correlacionado, indubitavelmente, com o PIB. O aumento da carga tributária ocorrida no Brasil ao longo das últimas décadas contribuiu com o aumento da renda das pessoas, em contrapartida favoreceu ainda mais o fenômeno da concentração de renda dos mais ricos no país.

A carga tributária regressiva que ocorreu, e que ainda ocorre, foi um fator que concebeu duas situações distintas: enquanto a desigualdade diminuía em função dos gastos em políticas públicas provenientes da arrecadação estatal, por outro lado as mudanças legislativas ratificavam a concentração de renda ainda mais.

Ainda que seja o tributo uma das maneiras de o Estado exercer a sua soberania perante a sociedade que possui o dever fundamental de pagar impostos, bem como o mecanismo de maior eficácia e importância no que tange a arrecadação, é preciso reavaliar os métodos da tributação, sobretudo o público alvo, vez que não há critérios precisos na forma como é conduzida a tributação sobre as diversas classes existentes no nosso país, sendo a atual conjuntura uma das principais fontes de concentração de renda e capital dos mais ricos sobre os mais pobres. Essa concentração pode causar um problema social, devendo o Estado atuar nesse sentido, pois, conforme relata Ribeiro (2015), a carga tributária de um país acaba demonstrando as opções legislativas sobre quanto tributar, a quem tributar e em que medida.

Dessa forma, é necessário que o Estado verifique as opções de tributação a serem elencadas de modo a não causar um problema social, tendo em vista que a redução de desigualdades sociais deve ser um dever do mesmo. E a Constituição Federal é 
um mecanismo importante nessa atuação, tendo em vista, sobretudo, os princípios constitucionais.

\section{A CONSTITUIÇÃO FEDERAL E SUA DISCIPLINA TRIBUTÁRIA ALIADA AOS PRINCÍPIOS CONSTITUCIONAIS}

O texto pátrio traz consigo um escopo do que o sistema tributário nacional determina sob um aspecto da relação entre o Estado em face dos particulares, iniciando a disciplina ao elencar quais serão os tributos instituídos, nos termos do art. 145, CF/88. A organização constitucional exerce um papel de estipulação das previsões das espécies tributárias, cabendo aos Estados Federados, ao Distrito Federal e aos Municípios se adequarem à primazia da Constituição. Tendo em vista o contingente de cobrança de impostos, sobretudo nas relações de consumo, que são o cerne da contribuição, é de se esperar, em matéria constitucional, que são os preceitos disciplinados a respeito desse tributo que são delineados, em sua maioria, nos escritos constitucionais.

Como bem fora elaborada numa estrutura basilar de fornecimento de subsídios fundamentais, a Constituição Federal de 1988 se posta, nesse sentido, como mecanismo garantidor, no que tange aos princípios gerais da tributação que geram efeitos diretos na relação jurídico-fiscal do Estado para com os seus contribuintes. Faz-se aqui, pois, a Lei Magna como força que assegura garantias aos contribuintes perante o Estado, a fim de impor limitações a este em razão do seu poder de tributar. Dessa forma, o art. 150, CF/88, visa tecer os princípios gerais do sistema tributário em função da vedação do poder público sobre alguns atos que por ventura não estiverem em consonância com a justa proteção do contribuinte.

Num terceiro momento, a Constituição carrega uma função de repartição das competências do poder de tributar, isto é, institui uma separação de atribuições para os exercícios institucionais de cada ente público, tendo estes parcelas específicas do poder de tributar, ratificando, deste modo, a legitimidade da soberania estatal sob a égide do paradigma do Estado Democrático de Direito. Não obstante, o texto constitucional reforça a unicidade do poder de tributar dos entes públicos, que se basta 
a estes a detenção exclusiva desse instituto. Essa característica sistêmica da Constituição é qualificada inclusive no Código Tributário Nacional, em seu art. 6으, dizendo ser essa questão uma "atribuição constitucional de competência tributária". Nesse sentido, é evidente a hierarquização existente no ordenamento jurídico, visto ser essa matéria um instrumento eficaz no que tange a organização dos elementos fundamentais da tributação e correspondências das funções dos entes federados no exercício do poder de tributar.

Todavia, na contramão de todas as instituições constitucionais que regem e amparam a tributação no Brasil, é de conhecimento constitucional que determinadas designações de tributos possuem uma fenda legislativa que necessitam de um preenchimento que as complemente e, assim, possa regular a instituição de tributos, mais precisamente de impostos, conforme preceitua o inciso VII do art. 153 da Constituição Federal de 1988, o qual é um dos componentes do núcleo de discussões acerca de uma proposta de reforma tributária.

O artigo supracitado carrega consigo uma tributação que, para ser instituída, é necessária uma regulamentação por meio de Lei Complementar. O grande problema é bastante simples: esta lei (ainda) não existe. Ou seja, o inciso VII do art. 153, CF/88, não possui eficácia, portanto é um termo vago e desprovido de gerar efeitos. O tributo, o qual o artigo em questão se refere, tem por disciplina a instituição do imposto sobre grandes fortunas. Segundo preceitua a Constituição:

Art. 153. Compete à União instituir impostos sobre (EC nำ 20/98 e EC no 42/2003)

(...) VII - grandes fortunas, nos termos de lei complementar.

Temos que a Lei Magna não suporta abarcar todos os institutos tributários, uma vez que, em determinadas situações, depende de uma relação interdisciplinar por meios ordinários, os quais não são aproveitados por vias constitucionais. Sendo assim, o caráter federalista da repartição das competências é, por vezes, levado a acarretar uma série de problemas que incidem diretamente na capacidade contributiva da população. Além de haver dependências legislativas, o federalismo fiscal permite 
instituições de tributos concebidos pelos entes federados, tais quais capazes de possuírem responsabilidades por grandes demandas de arrecadação tributária no país. É o que ocorre com o imposto ICMS (Imposto Sobre Circulação de Mercadorias e Serviços).

Neste caso, a Constituição acaba consistindo num mecanismo aquém da instituição de um imposto que é disciplinado por vias estaduais. O ICMS, um imposto incidente nas relações de consumo, possui um caráter essencialmente regressivo, sendo responsável por cerca de $20 \%$ de toda a arrecadação tributária do país e em torno de $7 \%$ do PIB, segundo dados do Inesc. O fato de incidir no consumo da população faz com que o ICMS seja uma das grandes razões da desigualdade social existente no Brasil, visto que ricos e pobres pagam a mesma alíquota do que consomem, sendo os consumidores os vetores que arcam com a maior parcela dos tributos em relação às suas rendas. A título de conhecimento, a instituição do ICMS tem como corolário o encarecimento de produtos alimentícios, bebida, bem como de serviços de bares e restaurantes e prestações de serviços de transporte.

Sendo assim, mudanças atreladas às propostas de reforma tributária providas de um caráter igualitário se fazem essenciais, porém não tendo de ser, necessariamente, feitas modificações constitucionais, afinal os problemas aqui postos, em sua maioria, nascem de instituições tributárias provenientes de leis ordinárias. Um dos exemplos que simbolizam essa situação ocorreu no governo Fernando Henrique Cardoso, quando este acabou por modificar a Lei 9.249/1995, prevendo a isenção do Imposto de Renda (IR) à distribuição de lucros e dividendos de pessoas físicas, desonerando os contribuintes ricos (sócios de bancos, por exemplo), enquanto o trabalhador (o bancário, neste caso) continua pagando o imposto, justamente na fonte que arrecada.

Vários princípios norteiam o Direito Tributário, como o, por exemplo, da anterioridade, da legalidade, da transparência, da irretroatividade e da transparência tributária. Porém, é importante que se discorra sobre um princípio basilar: o da capacidade contributiva. 
O artigo 145 e da Constituição Federal relata que "sempre que possível, os impostos terão caráter pessoal e serão graduados segundo a capacidade econômica do contribuinte". Dessa forma, percebe-se que está presente nas relações tributárias o princípio da capacidade contributiva. Este princípio é norteador das relações tributárias em nosso país, pois a partir deste percebe-se que a Constituição deve, quando todas as circunstâncias assim permitirem, cobrar impostos de acordo com a poder aquisitivo do contribuinte. Porém, uma breve percepção com relação a este princípio diz respeito ao mínimo existencial ou vital, em que, somente após o alcance do estabelecimento econômico além deste, pode se falar em capacidade econômica do contribuinte. Este pode ser conceituado como sendo:

[...] a parcela mínima de direitos constitucionais básicos para a sobrevivência digna do cidadão e de sua família, que se configura como um espaço do contribuinte intributável pelo Estado. Apesar de não estar expresso na Constituição, como ocorre com a vedação ao confisco, não se pode negar a proteção que ela the confere. (GASSEN; D'ARAÚJO; PAULINO, 2013, p. 221).

Um princípio também muito relevante para o Direito Tributário e que é muito discutido doutrinariamente, é o da igualdade tributária. Este se localiza na Constituição Federal, em seu art. $5^{\circ}$, onde se estabelece que "todos são iguais perante a lei, sem distinção de qualquer natureza". Assim, a interpretação doutrinária é que a igualdade estabelecida pela Constituição não é meramente formal, mas material. Significa tratar os igualmente os iguais e desigualmente os desiguais, na medida de sua desigualdade. É baseado neste princípio que se estabelece, por exemplo, as isenções relacionadas ao Imposto sobre a Propriedade de Veículos Automotores (IPVA) para deficientes físicos e taxistas, em determinados casos, por exemplo.

Existe outro princípio que é basilar no Direito Tributário e que está intimamente relacionado ao mínimo existencial, que é denominado de princípio de vedação ao confisco. A doutrina, em regra, relata que a tributação é compulsória por parte dos contribuintes. Porém, estabelece claramente que não se pode realizar uma tributação (incluindo-se a progressividade desta) excessiva de modo a confiscar certos bens do particular que são essenciais para a composição do mínimo vital deste. 
Porém, existe um entendimento, previsto no próprio artigo 145 da Constituição, de que não é possível realizar uma tributação particularizada sobre o contribuinte, pois existem casos em que tal perspectiva é impossível. Não é possível, por exemplo, realizar uma tributação particularizada para todas as pessoas que compram veículos automotores, no que diz respeito ao IPVA. Não é possível estabelecer um parâmetro particularizado dentre todas as pessoas que devem pagar o IPI. Se houvesse tal tratamento particularizado, a onerosidade para praticar tal ato faria com que tal procedimento se tornasse inviável. Dessa forma, por uma questão relacionada ao princípio de praticidade, busca-se tributar levando em consideração fatores um pouco mais gerais, com a finalidade de deixar mais célere e ágil a tributação.

\section{PROGRESSIVIDADE DA CARGA TRIBUTÁRIA EM FUNÇÃO DO ATUAL CARÁTER REGRESSIVO}

O atual sistema tributário brasileiro carrega consigo um caráter bastante injusto no que tange à maneira com a qual incidem os tributos. Muito se fala em reduzir a carga tributária que, de fato, é bastante elevada. Entretanto, o fator que gera a disparidade nas contribuições e consequente desigualdade social não está atrelado intrinsecamente à grande tributação, mas no modo como se dá essa tributação, sendo este um modelo amplamente regressivo.

Por tributação regressiva compreende-se o mecanismo de arrecadação que não se leva em conta o poder aquisitivo dos contribuintes, equiparando pobres e ricos no concernente à contribuição, fazendo gerar, dessa forma, um desfalque na capacidade pecuniária daqueles que possuem rendas mínimas, o que no fim causa um disparate ainda maior entre ricos e pobres. Em seu plano básico, o caráter regressivo da tributação contribui nada menos para que a desigualdade social se agrave ainda mais. A fim de combater essa desigualdade por meio dos próprios mecanismos da tributação, Thomas Piketty já identificava:

[...] O instrumento privilegiado da redistribuição pura é a redistribuição fiscal, que, por meio das tributações e transferências, permite corrigir a desigualdade das rendas produzida pelas desigualdades das dotações 
iniciais e pelas forças do mercado, ao mesmo tempo que preserva o máximo a função alocativa do sistema de preços. (RIBEIRO, 2015, p. 7).

A regressividade dos tributos favorece a incidência da tributação indireta sobre o consumo, fonte de maior arrecadação tributária no país. Isso faz com que, proporcionalmente, ricos paguem menos impostos que os pobres, assalariados, camadas médias da sociedade, somadas as eventuais elisões fiscais, sonegações e isenções como a citada anteriormente em relação à tributação por via de Imposto de Renda sobre lucros e dividendos.

$\mathrm{Na}$ ordem dos tributos diretos, tido o Imposto de Renda (IR) como o maior exemplo desse tipo de tributação, vale mencionar dados que demonstram a injustiça promovida pelo Estado em função dos seus contribuintes. A tabela do Imposto de Renda, no Brasil, se diferencia em relação a países desenvolvidos em dois pontos: a quantidade de faixas e a porcentagem das alíquotas. No Brasil, existem apenas 5 faixas (onde já tivemos 13 até 1985), 4 delas sendo de alíquotas, são elas: isenção para quem teve rendimentos tributáveis de até $R \$ 1.710,78$ mensais e alíquotas de $7,5 \%, 15 \%, 22,5 \%$ e $27,5 \%$, esta denominada como alíquota marginal, incidente em rendimentos a partir de $R \$ 4.271,59$. Nos países europeus e nos Estados Unidos, a tributação é estabelecida por meio de um regime conforme o aumento de renda, lugares onde a tributação do IR chega a cerca da metade dos rendimentos, como ocorre no Reino Unido, Holanda, Bélgica, Suécia, Áustria, dentre outros. Nada mais progressivo.

[...] Do ponto de vista da verdadeira regra de ouro, que se refere à acumulação total do capital nacional, o fato é que os países europeus jamais estiveram tão prósperos. Por outro lado, o que é certo, é muito vergonhoso, é que o capital nacional é extremamente mal repartido: a riqueza privada se apoia sobre a pobreza pública e, sobretudo, por consequência, há uma despesa muito maior em juros da dívida do que investimos, por exemplo, no nosso ensino superior. (RIBEIRO, 2015, p. 35).

Sendo assim, o Imposto de Renda é um tributo progressivo. Entretanto, o IR brasileiro possui apenas meros requintes de progressividade, em virtude das poucas faixas de incidência e da porcentagem pequena da alíquota marginal, de apenas $27,5 \%$, muito 
aquém do que é tributado nos países desenvolvidos. O Brasil é um dos países que menos tributam os ricos em relação aos países do G20, por exemplo.

Portanto, o termo progressividade remete à adequação dos tributos às diferenças de capacidade pecuniária existentes na população. A ideia da tributação progressiva é a de se efetivar uma justiça social e promover a paridade das condições de vida das pessoas a fim de desmantelar a desigualdade evidente na população brasileira. Em linhas gerais, o tributo progressivo consiste em "quem tem mais, paga mais".

No tocante às pretensões de se fazer uma reforma tributária no âmbito de sua progressividade, percebe-se que o Imposto de Renda é o melhor mecanismo de se alcançar uma justiça fiscal, visto que considera a capacidade contributiva do cidadão. Todavia, deve-se levantar em conta não só um fator de controle de progressão, mas uma rede que possa monitorar os vieses que resultam no fenômeno da concentração de renda, isto é, dirimir a renda, a herança, o patrimônio, quaisquer que sejam os pontos ligados ao favorecimento de riquezas exacerbadas e, de certo modo, inúteis. Em suma, objetiva-se com a progressividade o afastamento da efetivação do princípio da proporcionalidade num conceito estritamente liberal e que, ainda hoje, na vigência do paradigma do Estado Democrático de Direito, a aplicação da proporcionalidade é bastante presente em nosso sistema tributário, o que impede a tentativa de se realizar uma redistribuição de renda num contexto de igualdade meramente formal. Com isso, Piketty afirma:

[...] O imposto progressivo é uma instituição indispensável para fazer com que cada pessoa se beneficie da globalização, e sua ausência cada vez mais evidente pode levar a globalização a perder apoio. (...) Por essas diferentes razões, o imposto progressivo é um elemento essencial para o Estado Social: ele desempenha um papel fundamental em seu desenvolvimento e na transformação da estrutura da desigualdade no século $X X$, constituindo uma instituição central para garantir a sua viabilidade no século XXI. (RIBEIRO, 2015, p. 20). 


\section{TRIBUTAÇÃO INCIDENTE SOBRE CONSUMO X GRANDES FORTUNAS}

O Brasil tem a maior parte dos impostos que são recolhidos pelo Poder Público concentrados nas relações de consumo, envolvendo inclusive produtos industrializados, divergindo dos países desenvolvidos, que têm uma concentração maior de tributação sobre a renda, o imposto sobre as grandes fortunas e a herança. Nestes impostos não se torna presente o princípio da capacidade contributiva exclusiva a determinado consumidor. No nosso país, a questão não é necessariamente o fato de a nossa carga tributária ser alta, pois esta se mostra aquém da celebrada em países mais desenvolvidos. Vários economistas defendem a ideia de que a carga tributária não é tão alta. Ela é apenas mal distribuída. O sistema tributário brasileiro trabalha focando em retirar a tributação dos com menor capacidade contributiva, o que não contribui de forma progressiva para o sistema tributário do país.

Dessa forma, percebe-se que a tributação sobre determinados produtos, que é realizada de forma igual em todos os contribuintes que desejam obtê-los, faz com que o contribuinte com menor poder aquisitivo seja tributado de forma à qual o seu salário fique mais comprometido do que o contribuinte com maior capacidade econômica, o que influencia de maneira forte no princípio da capacidade contributiva e no mínimo existencial, uma vez que o contribuinte mais pobre terá uma porcentagem do seu salário corroída. Assim, tem-se percebido que uma economia que trabalhe com um recolhimento de tributos, baseada em produtos industrializados, desde os mais úteis, até as mais inúteis, tende a elevar a desigualdade social, bem como a concentração de renda, deixando os ricos com um maior poder aquisitivo do que os pobres. Ribeiro (2015, p. 34) afirma que "na quadra atual, $1 \%$ da população mundial detém $50 \%$ de toda a riqueza do planeta, enquanto a metade inferior da pirâmide possui menos de $5 \%$ da riqueza". Um posicionamento estabelecido por Gassen, D’Araújo e Paulino ajuda a esclarecer a questão descrita no parágrafo anterior:

[...] tomando como base o salário mínimo, por exemplo, observa-se que as famílias com renda de até dois salários mínimos pagam $48,8 \%$ da sua 
renda em tributos. Já as famílias com renda acima de 30 salários mínimos pagam aproximadamente $26,3 \%$, poupando relativamente mais. Assim, basicamente, o contribuinte destinou, em média, 132 dias do ano comercial para o pagamento de tributos. Os cidadãos mais pobres, no entanto, trabalharam o equivalente a 197 dias, enquanto os cidadãos mais ricos aportariam 106 dias, comparativamente. Em termos absolutos, portanto, a carga tributária incidente sobre as famílias de baixa renda é relativamente mais alta, reduzindo significativamente seu poder de compra e, com isso, desrespeitando o princípio da capacidade contributiva e afetando diretamente o mínimo existencial. (GASSEN; D'ARAÚJJO; PAULINO, 2013, p. 224).

Assim, seria uma alternativa para equilibrar a capacidade contributiva e o equilíbrio tributário e para a justiça fiscal, a contribuição sobre a herança e sobre as grandes fortunas.

Percebe-se que em países desenvolvidos, onde a tributação sobre a renda e a riqueza representa uma porcentagem maior da tributação recolhida, observa-se um Estado mais justo tributariamente, onde a economia se sustenta e o Estado, além de permitir a livre iniciativa, contribui para uma aplicação mais concreta da capacidade contributiva, ao recolher mais impostos das pessoas que possuem maior capital. Reginato e Jesus alegam que:

[...] um sistema tributário deve ser composto basicamente por impostos diretos sobre a renda, patrimônio e riqueza. Um sistema tributário formado quase que exclusivamente por impostos sobre o consumo, com alíquotas elevadas, estará pouco apto para distribuir a carga tributária, levando em conta a chamada capacidade contributiva. Seus efeitos serão regressivos na economia. Dessa forma, o sistema tributário contribui diretamente para uma maior concentração da renda nacional. (REGINATO; JESUS, 2016, p. 24).

Contudo, a falta de uma reforma tributária igualitária em nosso país por parte dos legisladores pode futuramente tender a uma ruptura do sistema tributário. Além disso, tal comportamento faria com que com o passar do tempo, o mínimo vital dos contribuintes com poder aquisitivo baixo poderia ser atingido, pois a necessidade pelo consumo aliada com a tributação do produto pode acabar por comprometer integralmente o seu salário. Assim sendo, a concentração acentuada de renda seria 
inviável ao próprio capitalismo, ao colocar poucas pessoas em situações muito confortáveis e a grande maioria em condições sub-humanas. Assim, Ribeiro descreve:

[...] é preciso que os setores empresariais adotem uma postura menos reativa a essas ideias, pois não será mais possível às classes dominantes brasileiras continuarem vivendo em oásis sem serem incomodadas pela desagregação do tecido social. A lógica de proteção das elites por meio do direito penal do inimigo já começa a dar sinais de cansaço, uma vez que não mais haverá polícia, ministério público ou magistratura que sejam suficientes para coibir os efeitos danosos de tamanha desagregação social, uma vez que no Brasil, há uma parcela significativa da população para quem a democracia, que a Constituição de 1988 trouxe aos setores médios, ainda não chegou. (RIBEIRO, 2015, p. 36).

Além disso, além da tributação relacionada às grandes fortunas, deve-se levar em consideração o aperfeiçoamento no que concerne à adoção de impostos que já existem, aumentando a sua abrangência em relação a estes. Observando este aspecto, podemos citar a incidência de IPVA sobre aeronaves particulares, como jatinhos, por exemplo, e embarcações particulares, como o iate, por exemplo. Se fizermos a interpretação analógica com relação a este imposto, observa-se que se um cidadão de classe média deve pagar um imposto sobre a propriedade de um carro popular que é adquirido por este, a partir do momento de sua compra (onde ocorre a incidência do fato gerador), nada mais justo que uma pessoa com uma renda bem elevada, com dinheiro suficiente para comprar uma grande embarcação ou jatinho, ser tributada com uma progressividade ainda maior do que a que compra este simples carro. Indo mais além, podemos levar em consideração de proprietários de carro não populares, que são tributados considerando o seu valor, onde se paga uma alíquota referente a este. Nada mais justo que um veículo não popular, que não seja terrestre, seja tributado sob essa mesma lógica.

Existe uma corrente doutrinária que diz que a tributação sobre aeronaves e embarcações não é possível devido ao fato de que estes se locomovem nos mares e no ar, sendo estes de propriedade da União e não dos estados, o que não permite a isenção do IPVA. Dessa forma, deve-se observar a iniciativa, por parte da própria 
União, de uma regulamentação específica a fim de se estabelecer uma nova forma de tributação para estes veículos.

Com relação aos impostos de herança, deve-se levar em consideração que a competência para criá-los e realizá-los é exclusiva dos Estados e do Distrito Federal. Dessa forma, têm-se o entendimento de que estes representam o sujeito ativo da relação tributária, ou seja, os credores, enquanto que são considerados os sujeitos passivos da relação tributária os recebedores do patrimônio deixado de herança (os contemplados pela herança), pois são considerados os devedores do fisco. Porém, o fato gerador da obrigação tributária incide somente após a aceitação da herança, pois, havendo renúncia desta, não haverá a incidência deste. Mas deve-se levar em consideração que o fato gerador inicia a partir da morte do indivíduo dono do patrimônio, sendo a obrigação de pagar o tributo das pessoas que aceitam o recebimento da herança.

No que concerne à base de cálculo do imposto, o valor dos bens que serão integrados nesta são o que forem avaliados na data de sua avaliação e não na data da abertura de sucessão. A alíquota referente ao tributo de herança é fixada pelos próprios Estados e pelo Distrito Federal, observado o limite máximo estabelecido pelo Senado Federal, que atualmente se encontra em $8 \%$. Para que haja um sistema tributário mais eficiente, é necessário que se tenha uma tributação mais forte com relação à causa mortis, pois assim, haveria uma captação de recursos de modo que as classes com maior poder patrimonial pagariam um valor maior e as com menor patrimônio um valor menor. Em um país de concentração de renda tão elevado como o nosso, é fundamental que haja não somente um aumento em quantidade das tributações sobre a herança, como também é fundamental que se adote a progressividade nesta. Pessoas que possuem um patrimônio com maior valor devem ser tributadas com uma alíquota maior do que pessoas que deixam um patrimônio menor (desconsiderando obviamente, os bens necessários ao mínimo essencial). 


\section{CONFLITO DE CLASSES}

O sistema tributário, ao valorizar a adoção de impostos indiretos, que têm a finalidade de captar recursos através do consumo, acaba dando uma significativa vantagem para as pessoas com maior poder aquisitivo, até porque elas vão ter uma menor parte de sua renda comprometida. Porém, os mais pobres sairão sempre em desvantagem, pois como dispõem de menor poder aquisitivo serão tributadas de modo que uma maior porcentagem do seu salário seja tributada em formas de consumo.

Porém, um dos grandes entraves que são encontrados na questão da tributação direita é com relação a aprovar tal projeto de lei que aumenta a tributação sobre grandes fortunas. No Brasil, embora todos tenham o direito de se candidatar a determinado cargo político, o sistema eleitoral facilita somente aos que tem um forte poder aquisitivo a serem eleitos ou a elegerem seus defensores. Assim, com o sistema político brasileiro como um todo sendo dominado por pessoas com maior patrimônio e renda, tende a dificultar a aprovação de tal medida em nosso país, uma vez que tal medida acabaria contrariando os interesses de tais, bem como dos seus representantes e financiadores. Com o imposto de renda, por exemplo, houve um debate de décadas até que este conseguisse ser instituído e, mesmo assim, sua progressividade se limita a uma alíquota de $27,5 \%$, sendo a progressividade limitada a determinado valor em dinheiro. Essa proporcionalidade atrapalha a captação de tributos, uma vez que tanto um servidor público de classe média que possui um salário de $\mathrm{R} \$ 6$ mil quanto um empresário portador de grande fortuna, com pró-labore mensal de $\mathrm{R} \$ 500$ mil, pagarão a mesma alíquota.

Observada essa questão, torna-se fácil identificar que a elaboração de um sistema tributário que privilegia o imposto direto em nosso país é realmente difícil de ser implementada, uma vez que a elite se posiciona de forma a não permitir tal sistema. Porém, se o Estado não trabalhar de forma a recolher este tributo direto dos setores, convertendo estes em políticas públicas e serviços públicos de qualidade, essa forma de tributação pode causar uma ruptura do sistema tributário brasileiro, como foi descrito anteriormente. 
Também não é prudente reinvestir grande parte da tributação em juros da dívida pública, pois, uma vez que o dinheiro é aplicado nestes, torna-se ainda maior a captação de recursos provenientes de impostos de fontes indiretas para serem pagos de forma direta, o que não contribui para o devido fluxo relacionado à tributação ideal. Dessa forma, seguindo procedimentos que já foram adotados em países europeus, como por exemplo, a Alemanha, a Suécia e a Dinamarca, as chances de se chegar a uma tributação com maior respeito à capacidade contributiva e ao mínimo existencial serão fortes.

\section{CONSIDERAÇÕES FINAIS}

A Constituição Federal estabeleceu, quando foi promulgada, normas que acabavam tendo, como uma de suas finalidades, controlar a regulamentação infraconstitucional tributária brasileira. Todas essas normas consideradas, sejam por regras ou por princípios, visavam estabelecer fundamentos para a efetividade de novas leis tributárias, compatíveis com o paradigma do Estado Democrático de Direito. Alguns princípios norteadores desta visão, como por exemplo, o da capacidade contributiva, são realmente essenciais em uma perspectiva de proteção ao contribuinte, de forma a garantir o mínimo existencial deste.

No entanto, algumas normas constitucionais dependem do estabelecimento de lei complementar para sua eficácia. Dessa forma, percebe-se que, em nosso país, a inércia do Poder Legislativo em estabelecer determinada lei, por exemplo, para influenciar a tributação direta, sobretudo das grandes fortunas, prejudica de forma drástica não só a efetividade da progressividade que deve ser adotada, mas também o sistema tributário como um todo, que se mostra, ao recolher maiores tributos através de impostos indiretos, falho e retrógrado, por diversos motivos.

Primeiramente, porque, ao realizar uma tributação dominante sobre os impostos indiretos, ele tributa da mesma maneira tanto os grandes empresários, com renda extraordinariamente grande, quanto as pessoas que conseguem se sustentar com apenas um salário mínimo, o que entra em extrema contradição com os princípios de justiça fiscal. 
Além disso, percebe-se que, realizando a tributação por modos indiretos, há uma captação menos eficiente por parte do Estado, uma vez que este não irá conseguir, através de Políticas Públicas e serviços estatais, reduzir a desigualdade social e a concentração de renda de forma eficiente, uma vez que as pessoas que mais sofrerão com a incidência do tributo serão as pessoas de menor renda, se tornando menos viável a ajuda estatal aos de baixa renda de um lado, enquanto do outro teremos a elevada tributação sobre os mesmos, enquanto os de maior renda não serão fortemente tributados.

Outra consequência que pode ser causada pela escolha em concentrar a tributação em impostos indiretos é a possibilidade de declínio do sistema capitalista. Uma vez que retiro uma maior tributação das pessoas que possuem menor renda, o mínimo existencial dessas pode ficar com o passar dos anos, extremamente comprometido, enquanto que as pessoas extremamente milionárias fiquem com uma tributação que comprometem cada vez menos a porcentagem de seu salário (ou pró-labore). Esta concentração excessiva de renda pode dar início a um grave problema social, uma vez que teremos cada vez menos pessoas com mais dinheiro e cada vez mais pessoas com menos.

Logicamente, uma alternativa viável para impedir esta concentração exorbitante de renda seria uma maior tributação, por parte do Estado, de tributação através de recursos diretos, como por exemplo, as grandes fortunas, a herança e a doação. A captação destes impostos por parte do Estado faria com que este exercesse uma forma de controle maior com relação à renda dos cidadãos, o que possibilitaria, além da diminuição da concentração de renda ao longo do tempo (pois este recolheria os tributos necessários para esta finalidade), a qualidade de vida das pessoas (uma vez que, com a captação destes tributos, haveria a utilização destes recursos financeiros em políticas estatais, governamentais e sociais para que serviços públicos de qualidade sejam implementados no país e possam, com o tempo, aumentar a eficiência de serviços essenciais, como a saúde e a educação).

Porém, encontra-se uma barreira muito forte para a instauração deste modo de captar tributos no país, uma vez que a elite brasileira controla ou financia grandes partes dos 
setores ligados ao Legislativo, buscando defender seus interesses. Assim, se torna, com o nosso Legislativo atual, cada vez mais difícil a implementação de captação de recursos que tenha a captação direta de tributos como propósito (a introdução do imposto de renda é um exemplo disso). Porém, deve-se ter o entendimento, por parte dos líderes do Estado, levando em consideração todos os poderes, que a tributação sobre pessoas com maior poder aquisitivo é essencial para que haja um equilíbrio tributário e uma maior manutenção do sistema capitalista, bem como uma maior qualidade de serviços públicos prestados à população como um todo.

Assim, deve-se buscar uma maior integração entre a sociedade e o Poder Público, a fim de se estabelecer uma reforma tributária que tenha como pilares essenciais a justiça e a equidade, de acordo com os princípios constitucionais previamente estabelecidos, principalmente o da capacidade contributiva, que deve nortear toda a visão da reforma tributária. Além disso, o papel do Estado nessa perspectiva deve ser essencial, de modo a dirigir do este processo, adequando as normas tributárias que posteriormente devem surgir (como o imposto sobre grandes fortunas, por exemplo) ao fiel cumprimento da Constituição Federal.

\section{REFERÊNCIAS}

BRASIL. Constituição da República Federativa do Brasil. Brasília: Senado Federal, 1988.

BRASIL. Presidência da República. Lei no 5.172, de 25 de outubro de 1966. Dispõe sobre o Sistema Tributário Nacional e institui normas gerais de direito tributário aplicáveis à União, Estados e Municípios. Brasília - DF, 1966.

GASSEN, Valcir. D'ARAÚJO, Pedro Júlio Sales. PAULINO, Sandra Regina da F. Tributação sobre Consumo: o esforço em onerar mais quem ganha menos. Disponível em <http://www.scielo.br/pdf/seq/n66/09.pdf>.

KHAIR, Amir. Imposto sobre Grandes Fortunas (IGF). Disponível em $<$ http://www.ie.ufrj.br/aparte/pdfs/akhair190308 2.pdf>. 
NETO, Alfredo Meneghetti. RÜCKE, Isabel Noemia Junges Rücke. Sistema tributário brasileiro: algumas considerações. Disponível em $<\underline{\text { https://revistas.fee.tche.br/index.php/indicadores/article/view/501/739>. }}$.

NETO, João de Freitas Machado. Tributação sobre a herança: a progressividade do imposto sobre a transmissão causa mortis e doação. Disponível em $<$ http://bdm.unb.br/bitstream/10483/10873/1/2015 JoaodeFreitasMachadoNeto.pdf>.

PIKETTY, Thomas. O Capital no Século XXI. Trad. Monica Baumgarten de Bolle.1. Ed.- Rio de Janeiro: Intrínseca, 2014.

REGINATO, Alexandre Orion. JESUS, Rafael Xavier de. Uma análise a respeito da regulamentação do imposto sobre grandes fortunas no Brasil. Disponível em: $<$ http://www.publicadireito.com.br/artigos/?cod=79ed69cea0c5acff $>$.

RIBEIRO, Ricardo Lodi. Piketty e a reforma tributária igualitária no Brasil. Disponível em

$<\underline{\text { http://www.e- }}$

publicacoes.ueri.br/index.php/rfptd/article/view/15587/11798>.

TORRES, Luciana de Oliveira. Análise do IPVA: aspectos gerais e controvertidos. $<$ http://www.emerj.tiri.jus.br/paginas/trabalhos conclusao/1semestre2011/trabalhos 12011/LucianadeOliveiraTorres.pdf>.

Enviado: Março, 2020.

Aprovado: Agosto, 2020. 